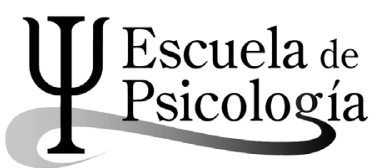

Wímb lu, Rev. electrónica de estudiantes Esc. de psicología, Univ. de Costa Rica. 10 (2): 9-17, 2015 / ISSN: 1659-2107

\title{
EL RETORNO DE LOS AFECTOS EN LA POLÍTICA
}

\author{
Affects return in polytics
}

Diego Carmona*

Resumen: Todo cuestionamiento, deliberación y reflexión por parte de las sociedades acerca de sus significaciones, sentidos y poderes, implica conflicto y afectividad. El presente trabajo circunscribe el análisis a la pregunta por el lugar de la afectividad en la política, centrándonos en distintos recorridos y aportes que intentan responder esta pregunta. Nuestro objetivo es reivindicar el papel de los afectos, en un contexto en el que priman aquellas formas de pensar la política en el ámbito de la "racionalidad"; perspectivas que impulsan la búsqueda de consensos racionalmente establecidos y que coinciden en ubicar a los afectos como aquello sobre lo que la política debe distanciarse, postulando la equivalencia entre afectividad e irracionalidad. Se recorrieron distintos abordajes, iniciando con los aportes de la primera etapa de la psicología de las masas, que sostendrán que la línea divisoria entre las formas racionales de organización social y los fenómenos de masas coincide en gran medida con la frontera que separa lo normal de lo patológico, así como la idea de que la distinción entre la racionalidad y la irracionalidad coincidiría ampliamente con aquella entre el individuo y el grupo para a continuación retomar los aportes de Sigmund Freud en "Psicología de las masas y análisis del yo", y sus conceptos de libido e identificación, centrales para pensar la formación de la masa así como para dar el giro de la idea de sugestibilidad a la de afectividad. Por último, introduciremos los aportes al debate contemporáneo de la politóloga belga Chantal Mouffe que nos permitirán reflexionar sobre la actual situación política en Europa y el avance de los llamados "neofascismos". No es la intención del presente trabajo agotar las relaciones posibles entre afectividad y política, sino ser una invitación a seguir profundizando en base a los desarrollos que han intentado pensar esta relación a lo largo de la historia. Por lo tanto, más que saldar el debate, nos proponemos aproximar las complejidades del mismo y ser un esbozo a la hora de desarrollar nuevos conceptos, ampliando así la frontera de lo pensable. Es nuestro propósito contribuir a desestigmatizar el rol de los afectos en la política y pensar la importancia de los mismos, ya no para reducirlos a un mero accidente o lugar marginal, sino para pensarlos en su verdadera e importante centralidad.

Palabras clave: Política, Psicoanálisis, afectividad, grupos, masas.

Facultad de Psicología-Universidad Nacional de Rosario, Estudiante de sexto año. Argentina. Correo electrónico: die_psico@hotmail.com

Recepción: 11/3/2015 Aceptación: 19/6/2015 


\begin{abstract}
All questioning, deliberation and reflection by communities about their meanings and powers, implies conflict and affection. This paper limits the analysis to the question of the place of emotion in politics, focusing on different routes and contributions that attempt to answer this question. Our goal is to reclaim the role of affect in a context in which those forms prevail thinking politics in the field of "rationality"; perspectives that drive the search for rationally established consensus and agree to locate the affections as that over which politics must distance postulating the equivalence between affectivity and irrationality. Different approaches were covered, starting with the input of the first stage of the psychology of the masses, who argue that the line between rational forms of social organization and mass phenomena largely coincides with the boundary between the normal pathological as well as the idea that the distinction between rationality and irrationality widely coincide with that between the individual and the group to then return the contributions of Sigmund Freud in "group Psychology and analysis of the Subject", and concepts of libido and identification, core training to think of the mass as well as to give the idea of turning the suggestibility of affection. Finally, we introduce the contributions to contemporary discussion of the Belgian political theorist Chantal Mouffe that allow us to reflect on the current political situation in Europe and the advance of "neo-fascism".

Is not the intention of this paper to exhaust the possible relationships between emotions and politics, but as an invitation to further deepen the basis of developments that have tried to think this relationship throughout history. Therefore, rather than settle the debate, we propose to approximate the complexities of it and be an outline when developing new concepts, extending the border of the thinkable. It is our aim to help destigmatize the role of affect in political thinking and the importance of them, not to reduce them to a mere accident or marginal place, but to think them in their true and important centrality.
\end{abstract}

Key Words: Politics, Psychoanalysis, affectivity, groups.

\title{
I. Introducción
}

¿Qué puede decirle el psicoanálisis a la política? ¿Qué puede tomar la política del psicoanálisis?. En principio, debemos dejar en claro qué entendemos por política. Adherimos a la concepción de política expresada por el filósofo y psicoanalista Cornelius Castoriadis (2008), quien establecerá una distinción entre el orden de lo político, y el de la política, adscribiendo el segundo al movimiento de lo instituyente, la fuerza capaz de establecer nuevas significaciones imaginarias sociales, y la capacidad de deliberar, cuestionar y reflexionar sobre lo instituido, apelando a la autonomía y a la creación. La política hace referencia a aquellos acontecimientos que se presentan como "rupturas" y que nos demuestran que ni la historia ni el ser se reducen a lo determinado. Ubicamos la política en el terreno de la imaginación. Imaginación no como falso reflejo del conocimiento verdadero, distorsión o falsificación, sino como sinónimo de creación. Son las sociedades las que crean sus significaciones imaginarias sociales y marcan diferentes momentos de la historia a partir del alzamiento de lo instituyente frente a lo instituido. Mientras que lo político hace referencia a las significaciones imaginarias sociales existentes, el poder explícito y el campo de lo instituido (Uribarri, 1992). 
Esta capacidad de deliberación, reflexión y cuestionamiento de las sociedades acerca de sus propios cimientos no es nunca sin conflicto y afectividad en juego en la misma. Es condición sine qua non de la discusión el establecimiento de tensiones y diferentes posturas que se presentan muchas veces de manera contrapuesta, presentándose la pretensión de "armonía" entre las mismas como una disolución de la pluralidad, es decir, una fundición en la homogeneidad que elimina las especificidades. Por afectividad entendemos las vivencias que engloban tanto los sentimientos como las emociones; los sentimientos carecen usualmente de las concomitancias somáticas fuertes propias de las emociones; son más suaves y duraderos que ellas, dicen menos en relación a la conducta motora y más al pensamiento y la imaginación. Las emociones son un constructo teórico conformado por una dimensión cognitiva (pensamientos, creencias), una dimensión motora, y una dimensión estrictamente fisiológica (Ballesteros Jiménez y García Rodríguez, 2006, p. 345).

En este sentido, creemos que preguntarse por la afectividad en el campo de la política es reivindicar el papel de los afectos en la misma, en un contexto en el que priman aquellas formas de pensar la política en el ámbito de la "racionalidad", que se postula enfrentada al ámbito de los afectos, formas que impulsan la búsqueda de consensos racionalmente establecidos y que coinciden en ubicar a los afectos como aquello sobre lo que la política debe distanciarse, postulando la equivalencia entre afectividad e irracionalidad. Diferencia que como veremos a continuación se presenta muchas veces además coincidiendo con la distinción entre individuo y grupo. Mientras que el individuo se correspondería con la racionalidad, el grupo sería el ámbito en el que se despliega la irracionalidad.

\section{La psicología de las masas: Taine y Gustave Le Bon}

En 1921, Sigmund Freud publica "Psicología de las masas y análisis del yo", escrito en el cuál discutirá con exponentes de la llamada "psicología de las masas" como Gustave Le Bon y Mc Dougall. Uno de los primeros teóricos de las masas que se centrará en el análisis de las masas que participaron de la Revolución Francesa fue Hypolite Taine. Ernesto Laclau (2005) citando a Susana Barrows sostendrá que Taine anticipa lo que se convertirá en el presupuesto indiscutible de los teóricos de las masas: concretamente, que la racionalidad pertenece al individuo, y que este pierde muchos de sus atributos racionales cuando participa de una multitud. Dentro de la sociedad, afirmará, el peligro de infección de las multitudes es mayor en algunos grupos que en otros: la aristocracia es menos 
propensa al contagio mental que las clases populares, y las mujeres y los niños son más propensos que los hombres. Ahora bien, no ha sido Taine sino Le Bon con quien Freud dialogará en su Psicología de las masas y análisis del yo. Afirma Laclau (2005) en relación a Le Bon:

Dos supuestos principales que fundamentan su pensamiento y que han dominado en gran medida las primeras etapas de la psicología de las masas. El primero es que la línea divisoria entre las formas racionales de organización social y los fenómenos de masas coincide en gran medida con la frontera que separa lo normal de lo patológico. A su vez, este primer supuesto está inserto en otro que sin duda está presente en Le Bon, pero también en la mayor parte de la literatura de su época relativa al comportamiento de las masas: la distinción entre la racionalidad y la irracionalidad coincidiría ampliamente con aquella entre el individuo y el grupo. El individuo experimenta un proceso de degradación social al volverse parte de un grupo. En sus palabras: por el mero hecho de formar parte de una multitud organizada, un hombre desciende varios rangos en la escala de la civilización. De manera aislada, puede ser un individuo cultivado; en una masa, es un bárbaro, esto es, una criatura que actúa por instinto (p. 46).

Sostendrá Le Bon (1945) la existencia de un alma colectiva en la que los individuos se fundirían al formar parte de la multitud, y adoptando la existencia del inconsciente a nivel social postulará que nuestros actos conscientes se derivan de un substratum inconsciente, formado fundamentalmente por influencias hereditarias. Este sustrato entraña los innumerables residuos ancestrales que constituyen el alma de la raza. En la multitud se borrarían las adquisiciones individuales y desaparecería la personalidad de cada uno de los individuos que la integran; la singularidad se fundiría en una homogeneidad, y esto tendría que ver con la puesta en juego de la uniforme base inconsciente, y la suspensión de la superestructura psíquica, la consciencia.

En la época de los primeros estudios de psicología de las masas, los debates en torno a la histeria y la sugestión se centraban en la polémica entre la Escuela de Salpetriére, cuyo principal representante era Charcot, y la Escuela de Nancy, entre cuyos principales representantes se encontraba Bernheim. Para Charcot, los fenómenos hipnóticos tenían una base estrictamente fisiológica y se entendía en un marco patológico, sólo se producía en el cuadro histérico. Por el contrario, la postura de la escuela de Nancy era más psicológica; se negaba a aceptar cualquier relación necesaria entre patología y sugestión hipnótica, y sostenía que toda persona, en un estado normal, podía experimentar esta última. Señalará Laclau (2005) que es característico de los valores que dominaban las elecciones teóricas de los psicólogos de masas que, de los diversos modos de comportamiento colectivo que tenían a su disposición, eligieran las categorías de la escuela de Charcot, que son precisamente las que acentúan en mayor medida la dimensión patológica. 


\section{Freud y el lazo libidinal}

Es a partir de los aportes de Freud que ya no es posible pensar en la masa dejando de lado la cuestión de los afectos. Este viraje en la manera de pensar la "psicología colectiva" lo realiza a través y a partir del concepto de libido

Nuestra labor se encaminará, pues, a hallar la explicación psicológica de la modificación psíquica que la influencia de la masa impone al individuo (...). Aquello que fuera de esto nos ofrecen, a título explicativo, las autoridades en sociología y psicología de las masas, se reduce siempre, aunque presentando bajo diversos nombres, a la misma cosa, resumida en la mágica palabra sugestión (Freud, 1924, p. 2575).

Freud señalará que la sugestión, que todo lo explicaba, carecía sin embargo de explicación, y propondrá presentando de esta manera un claro viraje en el estudio de la "psicología colectiva" el concepto de libido, que ya había aplicado al estudio de la psiconeurosis. La masa tiene que mantenerse unida en virtud de algún poder, y ese poder es Eros, que mantiene en cohesión todo lo existente. Para Freud, el hecho de que el individuo englobado en la masa renuncie a lo que le es personal y se deje sugestionar por otros, se debe a la necesidad de hallarse de acuerdo con ellos. Lo hace por el amor de ellos, por el amor de los demás.

Además de realizar este viraje empezará su análisis, no con las "formaciones espontáneas o desorganizadas" sino con instituciones de alta organización, para demostrar así como la afectividad, la fuerza del Eros, también reposa en los cimientos y fundamentos de las mismas. Contraponiéndose al resto de estudios sobre las masas, elegirá como punto de partida para sus investigaciones sobre las formaciones colectivas "masas artificiales", duraderas y con altos grados de organización como la Iglesia y el Ejército. Tanto en la Iglesia como en el Ejército, de acuerdo a los postulados de Freud, reina una misma ilusión: la de la presencia visible o invisible de un jefe que ama por igual a todos los miembros de la masa. En el caso del Ejército, el comandante en jefe; en el de la Iglesia, Cristo. De esa ilusión dependería la cohesión y conformación de la masa, y el desvanecimiento de la misma conllevaría la disolución de la colectividad.

Por lo tanto, la masa se constituye libidinalmente, en y por afectos, y a través de lo que Freud llamará Identificación. A diferencia de la imitación, de carácter consciente, la identificación es un proceso consciente que se produce a partir de un rasgo. En el caso de la masa, los individuos han reemplazado su ideal del Yo por un mismo objeto, a consecuencia de lo cual se ha establecido entre ellos una identificación.

Señalan Laplanche y Pontalis que el concepto de identificación fue utilizado muy pronto por Freud (1996, p. 184), sobre todo en relación con los síntomas histéricos. Los hechos llamados de imitación, de contagio mental, se conocían 
ciertamente desde mucho tiempo antes, pero Freud va más lejos al explicarlos por la existencia de un elemento inconsciente común a las personas entre las que se produce el fenómeno. En el caso de la masa ese rasgo común es el líder que vendría a reemplazar el Ideal del yo de los miembros del grupo. A pesar de los aportes de Freud en relación a la cuestión de la afectividad, en la actualidad priman formas de abordar lo político en términos racionalistas, como muchas de las teorías que abogan por "consensos racionalmente establecidos". Sin embargo, quien retomará en la era contemporánea la cuestión de los afectos en su obra y hará de ella un concepto central vinculado a la constitución de las identidades colectivas y a la especificidad de lo colectivo es la politóloga belga Chantal Mouffe, y a algunos de sus aportes en relación a estos puntos nos referiremos a continuación.

\section{El debate contemporáneo sobre los afectos: los aportes de Chantal Mouffe}

En En torno a lo político Chantal Mouffe sostendrá que muchos teóricos liberales se niegan a admitir la dimensión antagonista de la política y el rol de los afectos en la construcción de las identidades políticas, porque consideran que pondría en peligro la realización del consenso, al que consideran como el objetivo de la democracia. Sin embargo, Mouffe sostendrá que la especificidad de la democracia moderna radica en el reconocimiento y legitimación del conflicto y en la negativa a suprimirlo mediante la imposición de un orden autoritario. Abogará por el desarrollo de esferas vibrantes de agonismos, término que utiliza para designar el conflicto como constitutivo de lo político y distinguirlo del antagonismo. En tanto el agonismo implica un reconocimiento de la legitimidad del adversario, con quien se polemiza sobre diferentes modos de interpretar dos valores que sin embargo se comparten: la libertad y la igualdad, el antagonismo implica la conformación de un nosotros-ellos en torno a un modelo amigo/enemigo. En el antagonismo, propio de autoritarismos, el otro no es alguien con quien polemizo en base a diferentes interpretaciones, sino que es alguien que debo eliminar. La cuestión fundamental para la política democrática es para Mouffe pensar cómo se le puede dar a la dimensión antagónica- que refiere como constitutiva de lo político- una forma de expresión que sea compatible con la democracia.

La politóloga belga sostendrá que una democracia que funciona correctamente exige un enfrentamiento entre posiciones políticas democráticas legítimas. Esta confrontación debería proporcionar formas de identificación colectivas lo suficientemente fuertes como para movilizar pasiones. Si este modelo adversarial está ausente en la política, las pasiones de los sujetos no se 
expresan en formas compatibles con el sistema democrático, adquiriendo formas como el racismo o la xenofobia.

Cuando las pasiones políticas se vuelven difusas, se manifiesta un desafecto hacia los partidos políticos y tiene lugar un crecimiento de otros tipos de identidades colectivas, en torno a formas de identificación nacionalistas, religiosas o étnicas. Los antagonismos pueden adoptar diversas formas. (Mouffe, 2011, p. 137)

Podemos relacionar los conceptos desarrollados por Mouffe con la situación actual en algunos países europeos. En Francia ha resultado ganador en las últimas elecciones (Mayo de 2014) un frente con tendencias xenófobas liderado por Marine Le Pen, hija del histórico fundador del Partido Nacionalista, quien ha tenido declaraciones antisemitas y racistas. El fundador y jefe histórico del Frente Nacional, Jean-Marie Le Pen, en un acto en Marsella afirmó que los problemas de inmigración de Francia se resolverían "en tres meses" debido a la acción letal del Ébola. También ha lanzado frases como: hay riesgo de "invasión", "torrente migratorio" y se refirió al Islam como "la religión conquistadora" 1

Vemos aquí como la frontera no se construye en términos políticos, derecha e izquierda, sino que la frontera entre un nosotros y ellos se conforma a partir de criterios básicamente nacionalistas. Es así que el ellos que da agrupamiento al nosotros son los inmigrantes. Es así como partidos de la derecha en Francia movilizan afectividad en torno a la oposición a la inmigración, así como a la Troika, forma en la que se denomina en los medios de comunicación a un grupo de decisión formado por la Comisión Europea (CE), el Banco Central Europeo (BCE) y el Fondo Monetario Internacional (FMI).

Esta oposición a la Troika ha sido articulada en cambio, en España, por fuerzas de izquierda como Podemos, que en sólo unos meses logró ubicarse en el cuarto lugar en la votación para el parlamento europeo. Podemos construye un nosotros/ellos en términos específicamente políticos, al hablar de la casta para referirse al Partido Popular y al Partido Socialista y Obrero Español a quienes considerará parte de una misma esencia. Ubica así el conflicto en el terreno político, a partir de la diferenciación entre Pueblo y Casta.

Por tanto, para Mouffe todas las formas de la identidad política implican una distinción nosotros/ellos, la posibilidad de emergencia de un antagonismo nunca puede ser eliminada. Pues no sería más que una ilusión creer en el advenimiento de una sociedad en la que no hubiese conflictos ni antagonismos. Por tanto lo que debe hacer una política verdaderamente democrática es intentar impedir los surgimientos de identidades colectivas ligadas a la xenofobia, el racismo, y otras formas incompatibles con la democracia, mediante un modo diferente de establecimiento de la relación nosotros/ellos, basado en lo que Mouffe llamó agonismo. 


\section{Algunas conclusiones.}

En el presente trabajo hemos intentado esbozar un recorrido sobre algunos de los desarrollos sobre la cuestión de los afectos y su vinculación con la política.

En un principio, la llamada psicología de las masas pensó a los afectos insertándolos en un marco de irracionalidad y patología oponiéndolos de esta forma a supuestas formas "racionales" de organización social. Es con Psicología de las masas y análisis del yo, que los afectos empiezan a pensarse en aquellas instituciones que aparecían hasta entonces como "formas racionales de organización social". Los afectos no sólo están presentes en formas espontáneas, sino también en instituciones sólidas y con alto grado de organización, como la Iglesia y el Ejército. Freud irá incluso más lejos: son los afectos, la fuerza del Eros, los que mantienen unida a la masa, y los que mantienen consolidada a una institución. Sin el lazo amoroso con el líder y con los compañeros, la masa se disuelve.

Pensará la cuestión del liderazgo y la formación de la masa en torno al concepto de Identificación, que en Psicología de las masas y análisis del yo diferenciará de la imitación por su carácter inconsciente. La identificación implicará que los miembros de la masa ubiquen al líder en el lugar de Ideal del Yo, aquello a lo que el Yo debería aspirar para recobrar aquel estado de completud que se vivió y experimentó durante la infancia.

Como señalará Laclau (2005), la relación palabras/imágenes, el predominio de lo "emotivo" por sobre lo "racional", la sensación de omnipotencia, la sugestibilidad y la identificación con los líderes, constituyen rasgos reales del comportamiento de las masas. Sin embargo, pensar a los afectos como un polo opuesto al de una supuesta racionalidad y circunscribirlo a formaciones espontáneas, implica dejar de lado lo que Freud nos ha legado: pensar los afectos en toda formación social, y pensarlos como su base.

Por último, introducimos los conceptos elaborados por la politóloga belga Chantal Mouffe en torno a la constitución de las identidades colectivas en oposición a las formas más comunes de pensar la política en la actualidad. Para Mouffe, las identidades colectivas se conforman a partir de una diferenciación entre un nosotros y un ellos; y cuando esta diferenciación no se produce en términos propiamente políticos, la inevitabilidad del conflicto en la sociedad, hará que se procese bajo otras formas, ya no agonísticas sino antagónicas, como lo pueden ser la denominada "lucha contra el terrorismo", el fascismo y el "odio al inmigrante", así como el "odio religioso". Aventuramos finalmente posibles ejemplos en la coyuntura actual de Europa para entender los conceptos vertidos por la autora.

No es la intención del presente trabajo agotar las relaciones posibles entre afectividad y política, sino ser una invitación a seguir profundizando en base a los 
desarrollos que han intentado pensar esta relación a lo largo de la historia. Por lo tanto, más que saldar el debate, nos propusimos aproximar las complejidades del mismo y ser un esbozo a la hora de desarrollar nuevos conceptos, ampliando así la frontera de lo pensable. Es nuestro propósito con el presente trabajo contribuir a desestigmatizar el rol de los afectos en la política y pensar la importancia de los mismos, ya no para reducirlos a un mero accidente o lugar marginal, sino para pensarlos en su verdadera e importante centralidad para la vida en sociedad.

\section{Nota}

1. Paredes, J. (2014, 17 de junio). El peligro del ascenso electoral de los partidos de la ultraderecha en la UE. Diario La Vanguardia. Recuperado el 18 de Junio de 2014.

\section{Bibliografía}

Ballesteros, B., García, S. (2006). Procesos psicológicos básicos. España: UNED.

Castoriadis, C. (2008). El mundo fragmentado. La Plata: Terramar.

Freud, S. (1924). Obras completas. Traducción de Luis López-Ballesteros. Volumen VII. Madrid: Biblioteca Nueva.

Laclau, E. (2005). La razón populista. Buenos Aires: Fondo de Cultura Económica. Laplanche, J., Pontalis J. (1996). Diccionario de Psicoanálisis. Buenos Aires: Paidós.

Le Bon, G. (1945). Psicología de las multitudes. Buenos Aires: Albatros.

Mouffe, C. (2011). En torno a lo político. Buenos Aires: Fondo de Cultura Económica.

Paredes, J. (2014, 17 de junio). El peligro del ascenso electoral de los partidos de la ultraderecha en la UE. Diario La Vanguardia. Recuperado el 18 de Junio de 2014.

Uribarri F. (1992). Para pensar lo histórico social. Revista Zona Erógena, 12(10), pp. $11,66,67,68$.

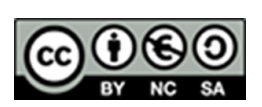

Esta obra está bajo una licencia de Creative Commons Reconocimiento

- NoComercial - CompartirIgual (by-nc-sa) 